\title{
The Impact Degrees of Basic Parameters on Repair Performance in Composite Patch Applications
}

\author{
Sefa Burak Yücel ${ }^{1}$, Memet Zor ${ }^{1}$, Halit Doğan²*, Mustafa Karamolla² \\ ${ }^{1}$ Dokuz Eylül University Engineering Faculty of Mechanical Engineering, İzmir, Turkey \\ ${ }^{2}$ Manisa Celal Bayar University Engineering Faculty of Mechanical Engineering, Manisa, Turkey \\ *halit.dogan@cbu.edu.tr \\ Received: 18 December 2018 \\ Accepted: 10 May 2019 \\ DOI: $10.18466 /$ cbayarfbe. 498884
}

\begin{abstract}
In this study, for composite patch repairs, the impact degrees of patch configuration and patch sizes on repair performance were determined and compared with each other. First, stress intensity factor (SIF) values were calculated by using the Finite Element Method for tensile loading in an aluminum plate with center cracks, in unpatched situation. In this model, the repair was made by forming single and double sided patches and adhesive volumes too. The SIF values are recalculated for different patch thicknesses, widths, and crack lengths. The criterion that determines the impact degrees of the examined parameters was accepted to be the reduction rate in the SIF values. The results show that even the most disadvantageous patch application contributes significantly to the repair performance and that the application itself is the most effective factor. The second most effective parameter is patch configuration; the patch sizes have much less impact degree.
\end{abstract}

Keywords: Stress intensity factor, composite patch, repair, fracture mechanics, finite element method.

\section{Introduction}

The use of composite materials in the repair of damaged structural elements is becoming increasingly widespread. Thanks to the different composite patches reinforced to the damaged areas of both composite [1, 2 3] and isotropic structures, it is aimed that the weakening strengths of these structures can be improved and reused. A lot of factors influence repair performance, such as material type, geometry, patch's configuration, number, shape and size, type and thickness of the adhesive, location and sizes of the damaged area. In the literature, it is possible to come across with many different scientific studies to determine these impacts.

By means of numerical or experimental [4-7] studies to determine the effects of different composite patch and adhesive configurations on the stress distributions and fatigue lives of repaired structures, it was aimed to suggest the best alternatives for repair.

Successful results have been obtained in the composite patch repair of the body and inner surface areas of different structural elements and especially aircraft by using adhesive [8-13]; in addition to increasing fatigue and corrosion resistance of structure, it has been found that patches easily adapted to complex shapes [14-16].

The repair performance, or, in other words, the advantage degree to which the repair will provide, is closely related to the rate of reduction of the second fracture risk in the damaged area. For this reason, after it is examined in terms of the fracture mechanics before and after repair, the calculation of parameters influencing crack opening such as stress intensity factor and the comparison of them with each other have a very important and determinant role in measuring repair performance. The studies carried out by handling with this approach are concentrated especially in the field of repair of isotropic structures through composite patches. In these studies, tensile loading (mode I), which is the most critical loading mode for crack opening, was discussed; the impacts of alternatives such as crack location, geometry, sizes, adhesive area properties and bonding techniques on repair performance. In thin aluminum plates with cracks originating from lateral circular notches, the effects of crack propagation behaviors for mod 1 and the patch sizes in the different configurations on crack bottom stress intensity factor were examined [17] by the finite element method and it has been inspected that there was an inverse proportional interaction between them. If the circular composite patches which were used to repair aircraft components are double-sided, it was shown that the stress intensity factor in the crack bottom significantly decreased [18], through three-dimensional finite element method. It was also determined that the patch shape is closely related to the repair performance with the same method, the octagonal patches are better than the rectangular, circular or elliptical forms in increasing the repair performance by reducing the crack bottom stress intensity factor; in addition, that the patch geometry in the shape of arrow [19], reduces the stress 
intensity factor. For the repair of center cracked metallic plates with double-sided composite patches, the rectangular patches are better than circular or elliptical patches. Moreover, another parameter that influences repair performance is the crack size. The impact of the same patch on repair performance for different crack sizes will change proportionately. Although different studies have been made in this respect, in the presence of central cracks in metallic plates, any significant work hasn't been found in the literature to determine the impacts of rectangular patches, depending on the size of the crack, on repair performance.

In this study, the impacts of single or double sided rectangular patches on the repair performance were examined according to the change of the crack size in a center cracked aluminum square plate. In addition to the crack length, patch width and patch thickness were also handled as variable parameters; in each examined situation, crack end stress intensity factors were compared with each other by calculating with three dimensional finite element analysis. In light of all results, factors were evaluated according to the impact degrees on the repair performance.

\section{Materials and Methods}

\subsection{Stress Intensity Factor (SIF)}

In a structure containing cracks, the stress values at the points of the crack bottom are much higher than the nominal $(\sigma)$ stress.

In a plate subjected to a tensile loading with a center crack (Figure 1), the stress at a point with $\mathrm{r}$ and $\sigma_{\mathrm{ij}}$ in the crack bottom can be calculated by the following formula;

$$
\sigma_{i j}=\frac{K_{I}}{\sqrt{2 \pi r}} f_{i j}(\varphi)
$$

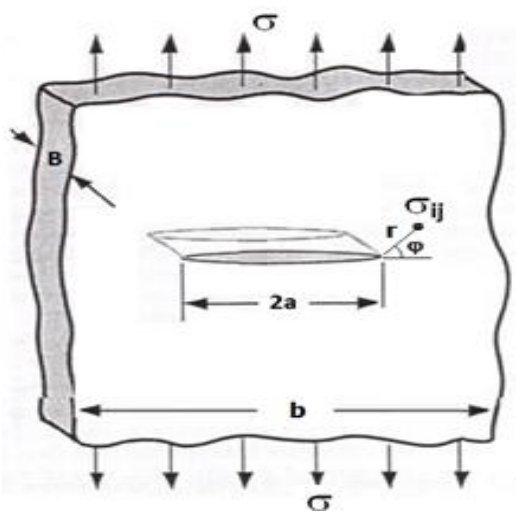

Figure 1. Plate exposed to pull load with center crack.

The value shown as $\mathrm{K}_{\mathrm{I}}$ in this formula is the stress intensity factor (SIF). Other parameters in the formula are related to the location of the point. The $\mathrm{K}_{\mathrm{I}}$ value can be calculated by the following formula in a plate including a crack with a width $\mathrm{b}$, length $2 \mathrm{a}$
Here, it is defined as the shape factor $\left(\frac{a}{b}\right)$. As the nominal stress $\sigma$ increases, the value of $\mathrm{K}_{\mathrm{I}}$ and the risk of crack opening will increase. After a certain value of $\mathrm{K}_{\mathrm{I}}$, the crack will grow unstably and the fracture event will occur. This critical value of $\mathrm{K}_{\mathrm{I}}$ is called fracture toughness $\left(\mathrm{K}_{\mathrm{IC}}\right)$ and is a characteristic feature which is independent of the sizes of the material. Then, the lower the $K_{I}$ value, the lower the risk of fracture. Thus, the improvement degree of composite patches can best be explained by the reduction rate of the $\mathrm{K}_{\mathrm{I}}$ value prior to the repair. After the repair, it can be said that the lower the $\mathrm{K}_{\mathrm{I}}$ value, the better the improvement and the higher the repair performance. For this reason, in these and similar studies, calculations for determining the $\mathrm{K}_{\mathrm{I}}$ values before and after repair are of great importance.

In this study, the repair of an aluminum square plate with a central crack along the thickness was handled with a single or double sided carbon / epoxy composite patch. Stress intensity factor (SIF) values were calculated for different crack sizes, patch widths and patch thicknesses.

These variable parameters and their impact degrees of the repair process on the repair performance are compared with each other. Firstly, in order to support the analyses, calculations for the unpatched plate and comparisons with a similar study were done. In the study of Kumar and Hakeem [20], sheet geometry (240 $\mathrm{mm} \times 240 \mathrm{~mm} \times 3 \mathrm{~mm})$, crack length $(2 \mathrm{a}=24 \mathrm{~mm})$, tensile loading $(\sigma=166.67 \mathrm{MPa})$, boundary conditions (Figure 1) and material properties [Table 1] were used; 2 and 3 dimensional quarter models (Figure 3) were established and the stress intensity factors (SIF) were calculated by the analyses made in the ANSYS program. It was seen that both 2 and 3 -dimensional analysis results were approximately the same and they were very close to the results of Kumar and Hakeem [Table 2]. Then, single or double sided rectangular composite patches and adhesive volumes were added to the same model. As shown in Figure 2, in addition to the plate sizes, the length $(48 \mathrm{~mm})$ of the patch which is perpendicular to the crack (in the direction of the y-axis) and the interface adhesive thickness $(1 \mathrm{~mm})$ were taken fixed. Patch thickness (tp), patch width (2Lp) and crack height (2a) were taken as variables. The results for single and double sided patch application were presented as graphs (Figure 4-6). Finally, the variable parameters are compared with each other according to their impact degrees on repair performance.

Table 1. Material Properties [20].

\begin{tabular}{|l|l|l|l|}
\hline \multirow{2}{*}{} & \multicolumn{3}{|l|}{ Stress Intensity Factor (SIF) } \\
\cline { 2 - 4 } & $\begin{array}{l}\text { Present } \\
\text { Study }\end{array}$ & $\begin{array}{l}\text { (Kumar \& } \\
\text { Hakeem, } \\
2000\end{array}$ & $\begin{array}{l}\text { Percent } \\
\text { Difference }\end{array}$ \\
\hline $\begin{array}{l}\text { 2D } \\
\begin{array}{l}\text { Unpatced } \\
\text { Model }\end{array}\end{array}$ & 35,259 & $\begin{array}{l}32,630 \\
\mathrm{MPa} \mathrm{m}^{1 / 2}\end{array}$ & $7,40 \%$ \\
\hline
\end{tabular}




\begin{tabular}{|l|l|l|l|}
\hline $\begin{array}{l}\text { 3D } \\
\text { Unpatced } \\
\text { Model }\end{array}$ & $\begin{array}{l}35,256 \\
\mathrm{MPa} \mathrm{m}^{1 / 2}\end{array}$ & $\begin{array}{l}32,630 \\
\mathrm{MPa} \mathrm{m}^{1 / 2}\end{array}$ & $7,40 \%$ \\
\hline
\end{tabular}

Table 2. Comparison of calculated SIF values for twodimensional unpatched Models.

\begin{tabular}{|c|c|c|c|}
\hline & \multicolumn{3}{|c|}{ Material Properties } \\
\hline & $\begin{array}{l}\text { Plate } \\
\text { (Aluminiu } \\
\mathrm{m} \text { ) }\end{array}$ & $\begin{array}{l}\text { Adhesiv } \\
\text { e }\end{array}$ & $\begin{array}{l}\text { Composite Patch } \\
\text { (Carbon/Epoxy) }\end{array}$ \\
\hline $\begin{array}{l}\text { Youngs } \\
\text { Modulu } \\
\text { s ( E ) }\end{array}$ & $71709 \mathrm{MPa}$ & $\begin{array}{l}2158 \\
\mathrm{MPa}\end{array}$ & $\begin{array}{l}\mathrm{E}_{1}=135000 \mathrm{MPa}, \\
\mathrm{E}_{2}=\mathrm{E}_{3}=9000 \mathrm{MPa}\end{array}$ \\
\hline $\begin{array}{l}\text { Poisson } \\
\text { Ratio (v } \\
\text { ) }\end{array}$ & 0,33 & 0,35 & $\begin{array}{l}v_{12}=0.3 \\
v_{23}=0.02\end{array}$ \\
\hline $\begin{array}{l}\text { Shear } \\
\text { Modulu } \\
\text { s ( G ) }\end{array}$ & $26958 \mathrm{MPa}$ & $799 \mathrm{MPa}$ & $\begin{array}{l}\mathrm{G}_{12}=\mathrm{G}_{13}=5000 \mathrm{MPa} \\
\mathrm{a}, \mathrm{G}_{23}=8000 \mathrm{MPa}\end{array}$ \\
\hline
\end{tabular}

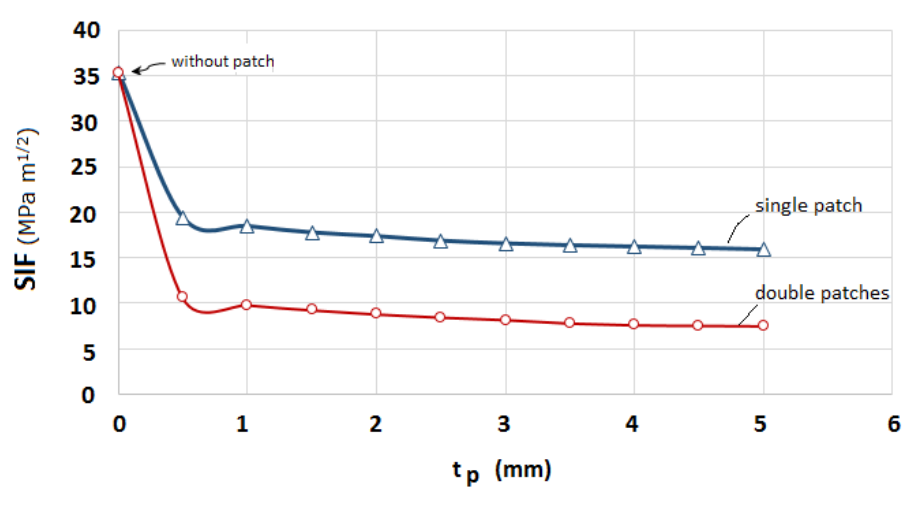

Figure 4. Effect of patch thickness (tp) on the stress intensity factor (SIF) $(2 \mathrm{Lp}=60 \mathrm{~mm}, 2 \mathrm{a}=24 \mathrm{~mm})$.

\section{Results}

Stress intensity factor (SIF) values obtained from the analyses for the unpatched center cracked plate and comparison with each other are shown in Table 2. In<smiles>Cc1ccc(C)c(N=[V])c1</smiles>
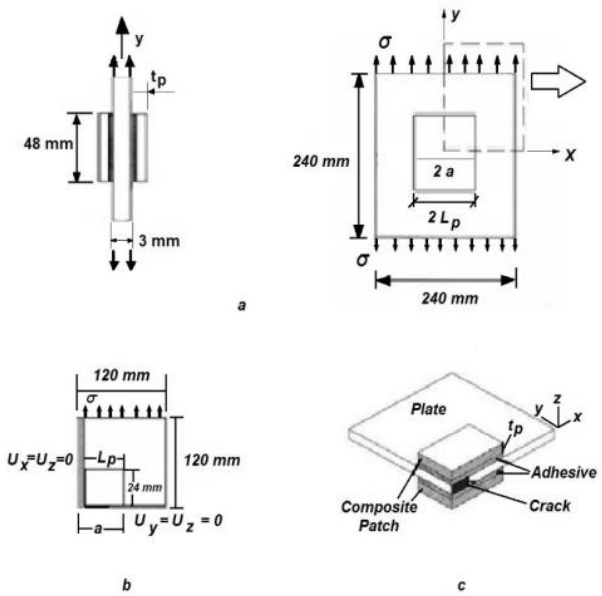

Figure 2. a-) Plate size with center cracks, patch application b-) Quarter model and boundary conditions c-) Quarter-model perspective view.

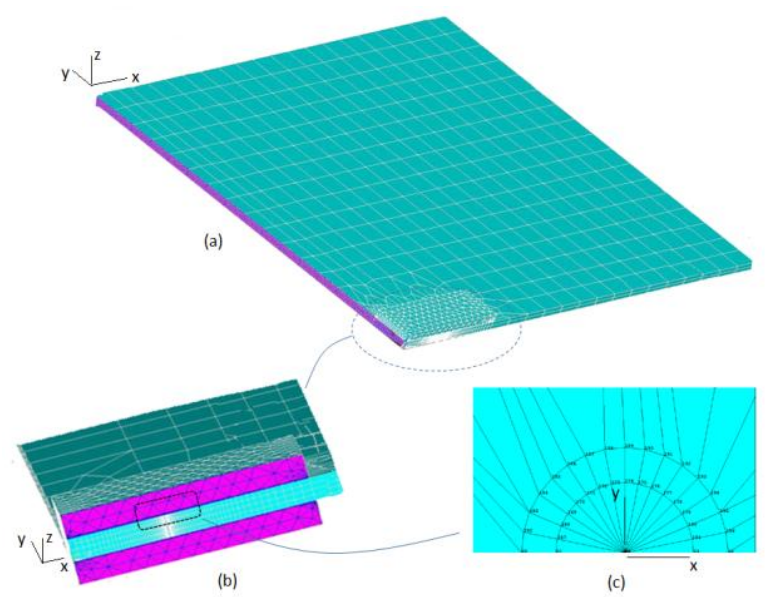

Figure 3. a-) Double-patched 3-dimensional quarterfined element model of center cracked plate b-) Patch zone c-) Top view of crack zone elements. present study, the results for 2 and 3 dimensional analysis was found at approximately the same value. At the same time, it is seen that the results are very close to the conclusions in Kumar and Hakeem's article [20]. This situation supports the accuracy of our analyses significantly.

If all the situations examined are taken into account, it is understood that the patch applications reduce the SIF values by a minimum of $45 \%$ compared to the unpatched situation and reduce the risk of secondary damage considerably. This is a general conclusion that patch applications, which are neat and error-free, will certainly benefit. This reduction rate of SIF value in single patch application can rise up to $55 \%$ depending on the patch size and the crack size. It is seen that the applied double-sided patches reduce the SIF value in the unpatched situation in the range of $70-80 \%$ and thus provided a much safer situation compared to the single patch. For example; for the $2 \mathrm{a}=24 \mathrm{~mm}, \mathrm{tp}=3 \mathrm{~mm}, 2 \mathrm{Lp}$ $=60 \mathrm{~mm}$, when the patch was applied single-sided, it reduced the SIF value $(60 \%)$ from $35,256 \mathrm{MPa} \mathrm{m}^{1 / 2}$ to $14,1 \mathrm{MPa} \mathrm{m}^{1 / 2}$; when the patch was applied doublesided it reduced the SIF value $(76.8 \%)$ to $7.68 \mathrm{MPam}^{1 / 2}$.

\section{Conclusions}

This study showed us that; in composite patch applications, the most important factor influencing repair performance is the application itself. That is, it does not matter what patch alternative the application is done with, if done properly, the SIF values fall to a large extent, the risk of secondary crack is significantly reduced, and the greatest benefit is provided by the application itself. As a result, in this study, the alternative in which single-sided and minimum patch thickness $(0.5 \mathrm{~mm})$ is preferred reduced the SIF values by $45 \%$ with respect to others, even though they had the least impact on repair performance. None of the other parameters provide such a high level of improvement. In other studies where the size and shapes of composite 
patches are compared with each other, this judgment indirectly reveals. For example, in the study of Kumar and Hakeem [20], while the SIF value in the unpatched situation was $32.63 \mathrm{MPa} \mathrm{m} 1 / 2$, it dropped to 3-8 MPa $\mathrm{m} 1 / 2$ interval for all examined patch shapes and sizes and, however, in this small range, the patch shapes and dimensions were compared with each other. This result importantly supports our above judgment.

The second important factor influencing repair performance is patch configuration, that is, the way in which the patch is applied on single-sided or doublesided. While the SIF values in the unpatched situation reduce in the range of $45-55 \%$ for the single-sided patch application, it decreases in the range of $70-80 \%$ for the double-sided patch application. For this reason, doublesided patches are much safer.

Patch thickness and width have much less impact on SIF values compared to these factors. As it can be understood from Figure 4 and Figure 5, after the SIF value drops by about $75 \%$ with the double-sided patch application, it can be slightly dropped in the range of 3$5 \%$ by increasing the thickness, it hardly changes with the increase of the width. Therefore, the use of larger patches covering even thicker or undamaged areas will have not any impact apart from increasing weight and cost. Keeping the patch sizes at the minimum level can be considered as a lower boundary in terms of repair performance provided that covering damage area.

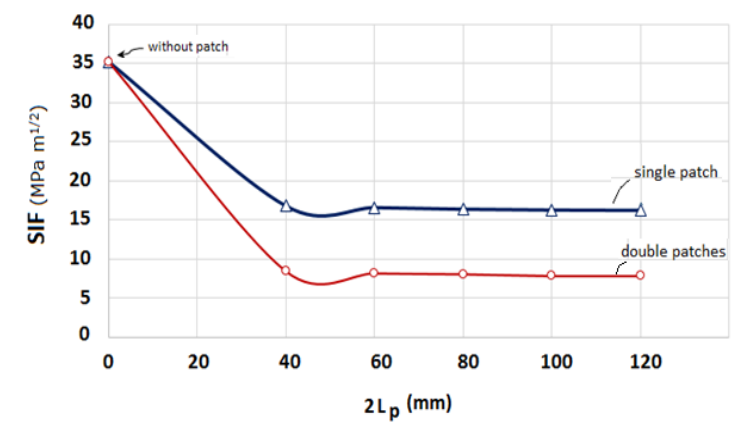

Figure 5. Effect of the patch width (2LP) on the stress intensity factor $(\mathrm{SIF})(2 \mathrm{a}=24 \mathrm{~mm}, \mathrm{tp}=3 \mathrm{~mm})$.

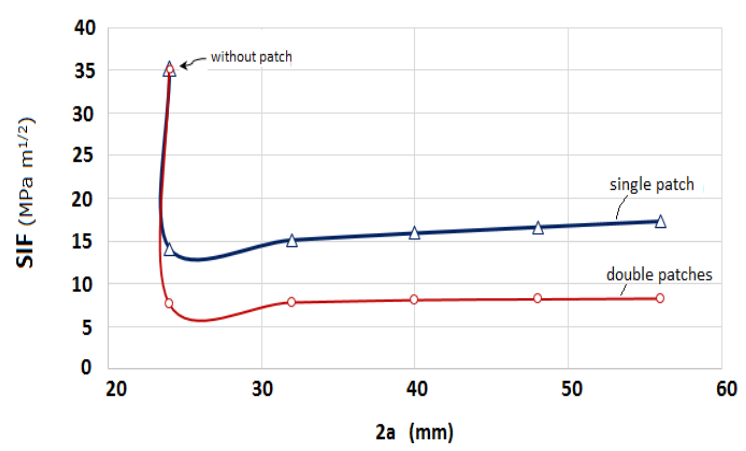

Figure 6. Effect of the crack length (2a) on the tensile strength factor (SIF) $(2 \mathrm{Lp}=60 \mathrm{~mm}, \mathrm{tp}=3 \mathrm{~mm})$.
Another factor that influences repair performance is the patch shape. However, other studies $[18,19,20]$ show that the impact of this factor is not as effective as the impact of patch application and configuration.

As a result, accurate and perfect composite patch application which will be done contributes significantly to the repair performance for all patch alternatives. However, the fact that the patch is double-sided is also the most effective way to further improve the repair performance. The patch shape and sizes are parameters that have less impact on the repair performance.

\section{Author's Contributions}

Sefa Burak Yücel: Performed the experiment and result analysis.

Memet Zor: Supervised the experiment's progress, drafted and wrote the manuscript.

Halit Doğan: Assisted in analytical analysis on the structure, result interpretation.

Mustafa Karamolla: Helped in manuscript preparation.

\section{Ethics}

There are no ethical issues after the publication of this manuscript.

\section{References}

1. Liu, X., Wang, G. 2007. Progressive failure analysis of bonded composite repairs. Composite Structure; 81: 331-340.

2. Charalambides, M.N, Hardouin, R, Kinloch, A.J, Matthews, F.L. 1998. Adhesively-bonded repairs to fibre-composite materials. Experimental, Composite Part A; (I): 1371-1381.

3. Hu, F.Z, Soutis, C. 2000. Strength prediction of patch-repaired CFRP laminates loaded in compression. Composite Science Technology; 60: 1103-1114

4. Gong, X.-J, Cheng, P, Rousseau, J, Aivazzadeh S. Effect of Local Stresses on Static Strength and Fatigue Life of Patched Composite Panels, 16th International Conferance Composite Materials, Kyoto, Japan, 2007, pp 1-7.

5. Marín, J.C, Barroso, A, París, F, Cañas, J. 2009. Study of fatigue damage in wind turbine blades. Engineering Failure Analaysis; 16 656-668.

6. Campilho, R.D.S.G, Moura, M.F.S.F, Pinto, A.M.G, Morais, J.J.L, Domingues, J.J.M.S. 2009. Modelling the tensile fracture behaviour of CFRP scarf repairs. Composite Part B Engineering; 40: 149-157.

7. Breitzman, T.D, Iarve, E.V, Cook, B.M, Lipton, R.P, Rouge, B Optimum Design a Composite Scarf Repair Patch Under Uniaxial Tensile Load, 17th International Conference on Composite Materials 2009, Edinburgh, İskoçya, 2009, pp 1-10.

8. Wang, Q.Y, Pidaparti, R.M. 2002. Static characteristics and fatigue behavior of composite-repaired aluminum plates. Composite Structure; 56: 151-155.

9. Belhouari, M, Bachir Bouiadjra, B, Megueni, A, Kaddouri, K. 2004 Comparison of double and single bonded repairs to symmetric composite structures: A numerical analysis. Composite Structure; 65 : 47-53.

10. Kumar, A.M, Ripudaman, S. 3D Finite Element Modelling of a 
Composite Patch Repair, 9th International Conference in Fracture, (ICF9), Sydney, Australia, 1997, pp 215-216.

11. Yang, C, Huang, H, Tomblin, J.S, Sun, W. 2004. Elastic - Plastic Model of a dhesive-bonded single-lap composite joints. Journal of Composite Material; 38: 293-309.

12. Baldan, A. 2004. Adhesively-bonded joints and repairs in metallic alloys, polymers and composite materials: Adhesives, adhesion theories and surface pretreatment. Journal Material Science: 39:1-49.

13. Campilho, R.D.S.G, Moura, M.F.S.F, Domingues, J.J.M.S. 2005. Modelling single and double-lap repairs on composite materials. Composite Science Technology; 69: 1948-1958.

14. Okafor, A.C, Bhogapurapu, H. 2006. Design and analysis of adhesively bonded thick composite patch repair of corrosion grind-out and cracks on 2024 T3 clad aluminum aging aircraft structures. Composite Structure; 76: 138-150.

15. Seo, D.C, Lee, J.J. 2002. Fatigue crack growth behavior of cracked aluminum plate repaired with composite patch. Composite Structure; 57: 323-330.

16. Denney, J.J, Directorate, F.D, Air, W, Base, F. 1997. Characterization of disbond effects on fatigue crack growth behavior in aluminum plate with bonded composite patch. Engineerig Fracture Mechanic; 57: 507-525.

17. Ouinas, D, Hebbar, A, Bouiadjra, B.B, Belhouari, M, Serier, B. 2009. Numerical analysis of the stress intensity factors for repaired cracks from a notch with bonded composite semicircular patch. Composite Part B Engineering; 40: 804-810.

18. Albedah, A, Bouiadjra, B.B, Mhamdia, R, Benyahia, F, Es-Saheb, M. 2011. Comparison between double and single sided bonded composite repair with circular shape. Materials Designe; 32: 996-1000.

19. Ramji, M, Srilakshmi, R, Bhanu Prakash, M. 2013. Towards optimization of patch shape on the performance of bonded composite repair using FEM. Composite Part B Engineering; 45: 710-720.

20. Kumar, A.M, Hakeem, S. A. 2000. Optimum design of symmetric composite patch repair to centre cracked metallic sheet. Composite Structure; 49: 285-292. 